\title{
ATIVIDADE ALIMENTAR DE ESPÉCIES DE PEIXE DO RIO TIBAGI, RELACIONADA COM O DESENVOLVIMENTO DE GORDURA E DAS GÔNADAS
}

\author{
Sirlei Terezinha Bennemann ${ }^{1}$ \\ Mário Luís Orsi ${ }^{1}$ \\ Oscar Akio Shibatta ${ }^{1}$
}

\begin{abstract}
FEEDING ACTIVITY AND ITS RELATIONS WITH FAT AND GONADAL DEVELOPMENT OF FISH SPECIES FROM TIBAGI RIVER. The fish assemblage in a stretch of Tibagi river was studied during the period of one year, throught monthly sampling. It was observed that four fish species (Schizodon intermedius Garavello \& Britski, 1990, Acestrorhynchus lacustris Reinhardt, 1874, Pimelodus maculatus Lacépède, 1803 and Steindachnerina insculpta Fernandez-Yepez, 1948) were very frequent and they represent all the main trophic groups. In order to characterize feeding activity, fat storage and reproduction the means degree of repletion, fat and maturation, obtained for each species in each month were compared among the four fish species. Steindachnerina insculpta, a detritivovous species was the one with the highest feeding activity while $A$. lacustris, a piscivorous fish, showed the lowest feeding activity. For these two species it was clearly observed a sequence of events: higher feeding activity followed by higher fat storage followed by reproduction, that was not observed for $P$. maculatus and $S$. intermedius. The variations in feeding activity and fat storage showed by $P$. maculatus and $S$. intermedius might be related to their diets.

KEY WORDS. Fish, feeding activity, gonadal development, Tibagi river, Paraná
\end{abstract}

Nos rios neotropicais os estudos relacionando atividade alimentar, desenvolvimento de gordura e reprodução dos peixes, enfocam, de uma maneira geral, como dependentes do ciclo hidrológico, quando ocorrem períodos bem marcados de cheia e seca. Assim na época das chuvas é quando ocorre a maior atividade alimentar e também o armazenamento de gordura para, em seguida ocorrer a desova. Nesta situação, o alimento dos peixes é principalmente de origem alóctone, proveniente das matas e que se torna acessível e abundante na época das chuvas. Em estudos dos peixes de rios da região amazônica esses aspectos são mencionados por GOULDING (1980), JUNK (1985) e LOWE-MCCONNELL (1987) e na bacia do rio Orinoco por MACHADO-ALLISSON (1992).

No entanto, além dos fatores hidrológicos, vários fatores biológicos podem estar relacionados. Goulding (1980) menciona que as diferentes dietas, bem como a natureza e origem do alimento, e o porte da espécie devem ser considerados. JUNK (1985) associa o desenvolvimento de gordura e sua sazonalidade à migração e

1) Departamento de Biologia Animal e Vegetal, Centro de Ciências Biológicas, Universidade Estadual de Londrina. 86051-970 Londrina, Paraná, Brasil. 
reprodução e GoDINHo (1994) atribui que o desenvolvimento de gordura tem ligação com a reprodução e não com as flutuações do nível da água.

Portanto, é importante que cada habitat e o conjunto desses fatores hidrológicos e biológicos que coordenam essa relação sejam considerados. Assim, durante o período estudado no rio Tibagi, na localidade Sertanópolis, que caracterizou-se por não apresentar épocas marcantes de cheia e seca e sem grandes variações do nível da água, propos-se a caracterizar as espécies Schizodon intermedius Garavello \& Britski, 1990 (herbívora), Acestrorhynchus lacustris (Reinhardt, 1874) (piscívora), Pimelodus maculatus Lacépède, 1803 (onívora) e Steindachnerina insculpta (Fernandez-Yepez, 1948) (detritívora) quanto às médias mensais do grau de repleção (GR), do grau de gordura envolvendo o trato digestivo (GG) e do grau de maturação (GM) e analisar a variação destes parâmetros durante o período estudado. Além disso, verificar a variação destes parâmetros em relação a variação da pluviosidade, nível da água e temperatura do ar e da água.

\section{MATERIAL E MÉTODOS}

\section{Área de coleta}

A bacia do rio Tibagi localiza-se na região centro-norte do Estado do Paraná, Brasil, entre os paralelos $23^{\circ}$ e $25^{\circ} 30^{\prime} \mathrm{S}$ e meridianos $51^{\circ}$ e $49^{\circ} 30^{\prime} \mathrm{W}$. Com mais de 65 afluentes e centenas de subafluentes, possui uma extensão de $550 \mathrm{Km}$.

O trecho da localidade estudada (Fig. 1), Sertanópolis, situa-se na região final da planície e tem influência do represamento do rio Paranapanema, onde o rio Tibagi deságua. Neste trecho, de pouca correnteza, a largura média é de $500 \mathrm{~m}$ e, na sua porção central, a profundidade pode atingir até $25 \mathrm{~m}$. A área amostrada não apresenta mata ciliar mas possui abundante vegetação aquática nas pequenas baias (composta por Eichhornia crassipes Marth Solms, Salvinia auriculata Aublet, Pistia sp.), Ciperaceae, Gramineae e Polygonum spectabile Martius enraizadas nas margens. O solo é utilizado exaustivamente com cultivares, que muitas vezes são plantadas até as margens do rio.

\section{Nível da água, nível pluviométrico e temperaturas (ar e água)}

O nível da água durante o período (Agosto/1992 a Julho/1993), no trecho estudado, não variou mais que um metro. Em dezembro foi o mês em que as águas estiveram mais baixas.

As chuvas foram abundantes na maioria dos meses e o menor valor de pluviosidade foi verificado em dezembro. Nos meses setembro, outubro, novembro, janeiro e fevereiro foram verificados os maiores valores de pluviosidade, conforme figura 2 .

A distribuição dos valores mensais das temperaturas do ar e da água (superfície e fundo) encontram-se na figura 3 . Os valores correspondem médias de temperaturas verificadas no período de 24 horas em cada mês de coleta. As médias de temperatura do ar variaram entre $16,2^{\circ} \mathrm{C}$ a $29^{\circ} \mathrm{C}$ e as da água (superfície e fundo) tiveram variações entre $16,8^{\circ} \mathrm{C}$ a $28^{\circ} \mathrm{C}$ e $16,7^{\circ} \mathrm{C}$ a $26,6^{\circ} \mathrm{C}$, respectivamente. 


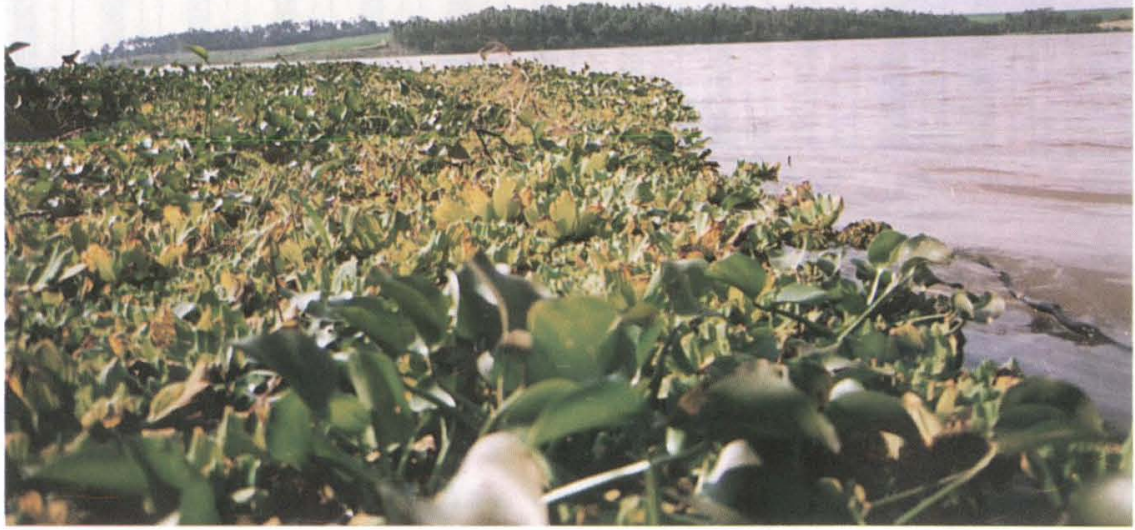

Fig. 1. Vista geral do trecho do rio Tibagi na localidade Sertanópolis, Paraná. Vegetação aquática característica.

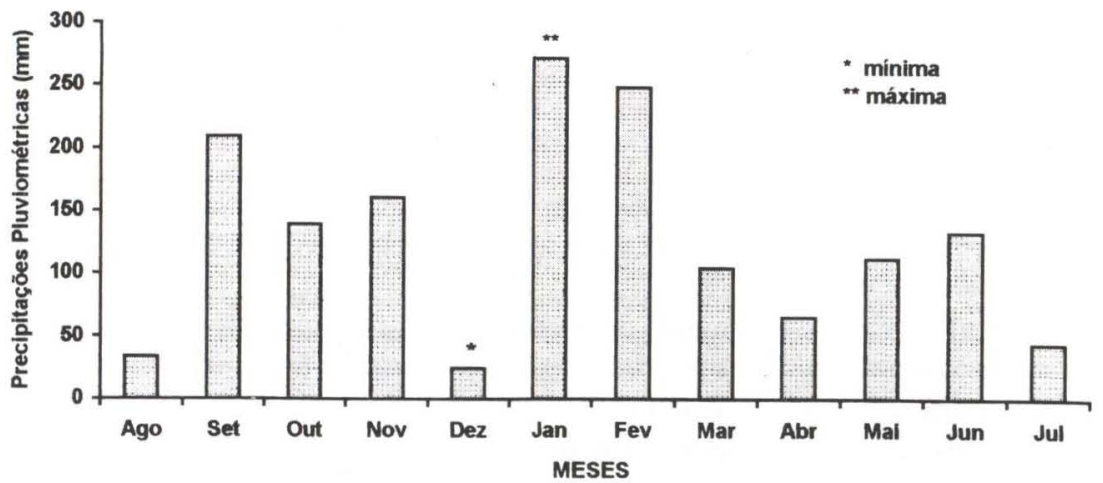

Fig. 2. Valores mensais da precipitação pluviométrica $(\mathrm{mm})$ na região de Sertanópolis. Fonte EMATER, Sertanópolis, Paraná.

\section{Metodologia}

As espécies e amostras foram coletadas mensalmente no período de agosto de 1992 a julho de 1993. Os peixes foram capturados com redes de espera (com malhas variando de 2 a $10 \mathrm{~cm}$ entre nós opostos), durante um período de 24 horas e revisões de quatro em quatro horas. Em laboratório de campo, cada exemplar foi dissecado para estimar a quantidade de gordura, o grau de repleção do estômago e identificar o estágio de maturação gonadal. 


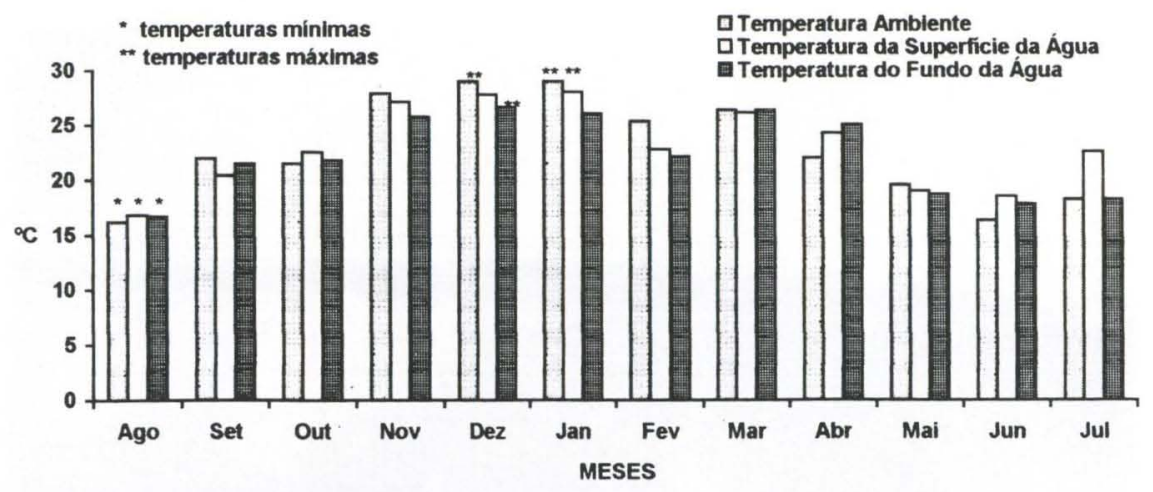

Fig. 3. Distribuição das temperaturas médias mensais (ambiente, água: superfície e fundo).

Um total de 793 exemplares foram analisados: 295 Schizodon intermedius, 207 Acestrorhynchus lacustris, 156 Pimelodus maculatus e 135 Steindachnerina insculpta.

Para determinação dos graus de repleção (GR) e gordura (GG) foi utilizada a escala conforme YABE \& BENNEMANN (1994).

Para determinação do estádio de maturação gonadal foi utilizada a seguinte classificação: I (imaturo), II (repouso), III (maturação), IV (maduro), V (desova) e VI (desovado), segundo SANTOS (1982).

As médias dos graus de repleção (GR), gordura (GG) e maturação (GM) mensais foram calculadas empregando-se a expressão adaptada de SANTOS (1982):

$$
G R, G G, G M=\frac{\sum(i . f a)}{N}
$$

onde: (i) número de pontos atribuídos (de 1 a 4 para repleção, de 1 a 3 para a gordura e de 1 a 6 para maturação); (fa) frequêencia absoluta de estômagos com grau "i"; (N) número de indivíduos analisados

Para o grau de maturação os pontos foram atribuídos da seguinte maneira [os mesmos graus atribuídos por SANTOS (1982)]: Estádio I = grau 1 (imaturos, não fizeram parte da análise); Estádio II = grau 2 ( repouso); Estádio III = grau 3 (maturação); Estádio IV = grau 4 (maduro); Estádio V = grau 5 (desova); Estádio $\mathrm{VI}=$ grau 6 (desovado).

Foram considerados em atividade reprodutiva os indivíduos encontrados em estágios maduro, desova e desovados.

\section{RESULTADOS}

\section{Atividade alimentar}

Dos espécimes analisados, foram registrados com estômagos vazios: $54,4 \%$ de Schizodon intermedius, 76,5\% de Acestrorhynchus lacustris e 39,5\% de Pimelodus maculatus. Em Steindachnerina insculpta, todos os exemplares analisados estavam com conteúdo estomacal (Fig. 4). 


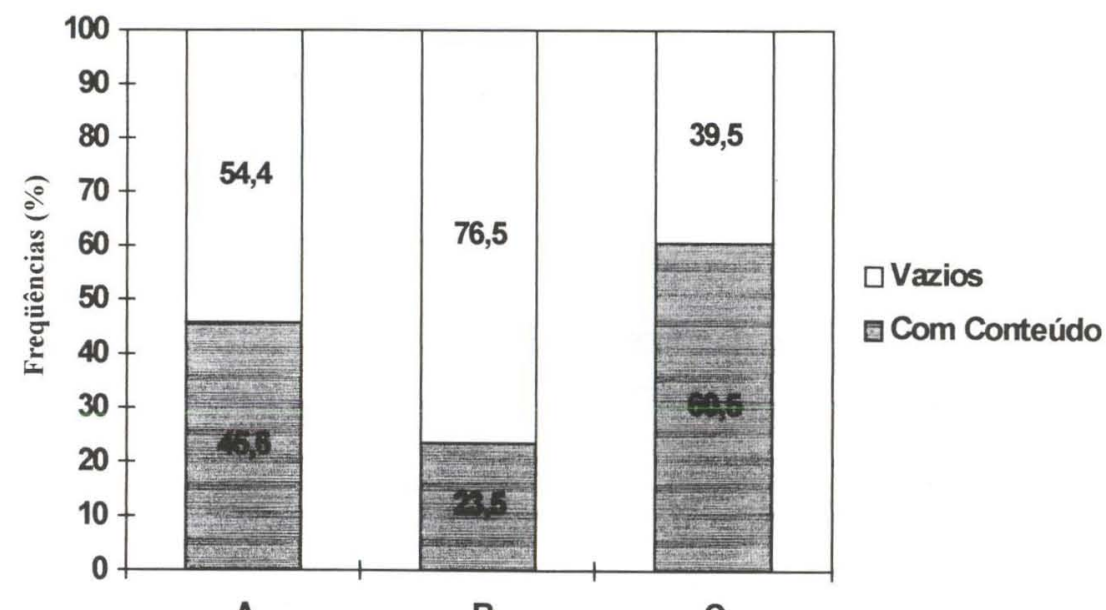

A

B

C

Fig. 4. Freqüências relativas de estômagos com conteúdo e vazios, em (A) Schizodon intermedius, (B) Acestrorhynchus lacustris, (C) Pimelodus maculatus e (D) Steindachnerina insculpta.

A distribuição das freqüências relativas dos exemplares com conteúdo estomacal durante os meses do ano foi superior a $50 \%$, com exceção de outubro, dezembro e julho para $S$. intermedius e outubro e julho para $P$. maculatus. As freqüências relativas de estômagos com conteúdo para A. lacustris, foram inferiores a $50 \%$ em todos os meses do ano.

A soma das freqüências relativas dos graus de repleção 1 e 2 foi superior a $80 \%$ para $S$. intermedius, $P$. maculatus e $S$. insculpta (Fig. 5). Para A. lacustris, as freqüências relativas dos graus de repleção 1,2 e 3, ficaram distribuídas com valores semelhantes (Fig. 5).

Na comparação com a média 1,0 (média das médias do grau de repleção das quatro espécies) verifica-se que $S$. insculpta teve em todos os meses médias do grau de repleção acima de $1,0, S$. intermedius e $P$. maculatus tiveram suas maiores freqüências relativas entre as amplitudes de variação 1 a 1,5 e A. lacustris, teve todas as médias abaixo de 1,0 (Fig. 6).

\section{Reprodução e desenvolvimento de gordura em cada espécie}

\section{Schizodon intermedius}

Foram verificados espécimes em atividade reprodutiva nos meses de dezembro, janeiro, fevereiro e maio. Os valores da média do GM foram baixos, pois a grande maioria dos exemplares estavam em maturação (Fig. 7A). Nos meses de atividade reprodutiva (com indivíduos em estagios maduro, desova e desovado) foram verificados poucos exemplares.

$\mathrm{Na}$ figura $7 \mathrm{~A}$, podem ser verificadas também, as médias dos graus de gordura que foram superiores ao valor $1,0 \mathrm{em}$ todos os meses e os picos foram verificados em outubro, maio e julho, meses em que a atividade alimentar teve valores do GR baixos $(0,38,0,70$ e 0,65 respectivamente). 

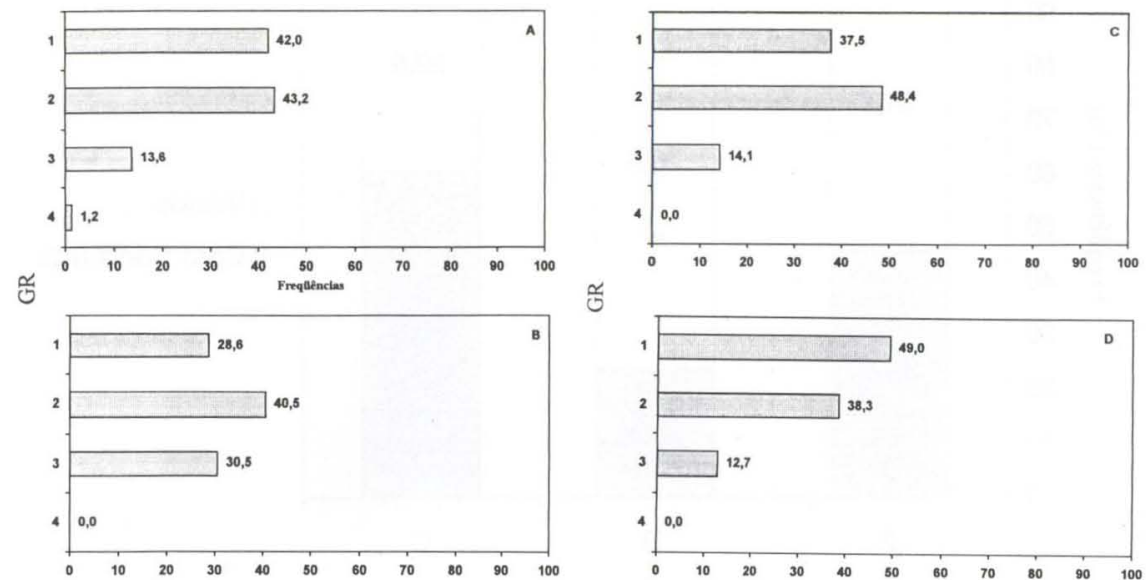

$\frac{\alpha}{0}$

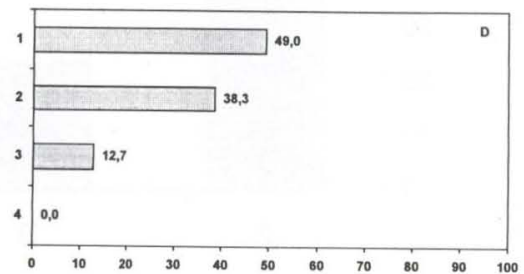

Fig. 5. Freqüências relativas dos graus de repleção (GR) em (A) Schizodon intermedius, (B) Acestrorhynchus lacustris, (C) Pimelodus maculatus e (D) Steindachnerina insculpta.
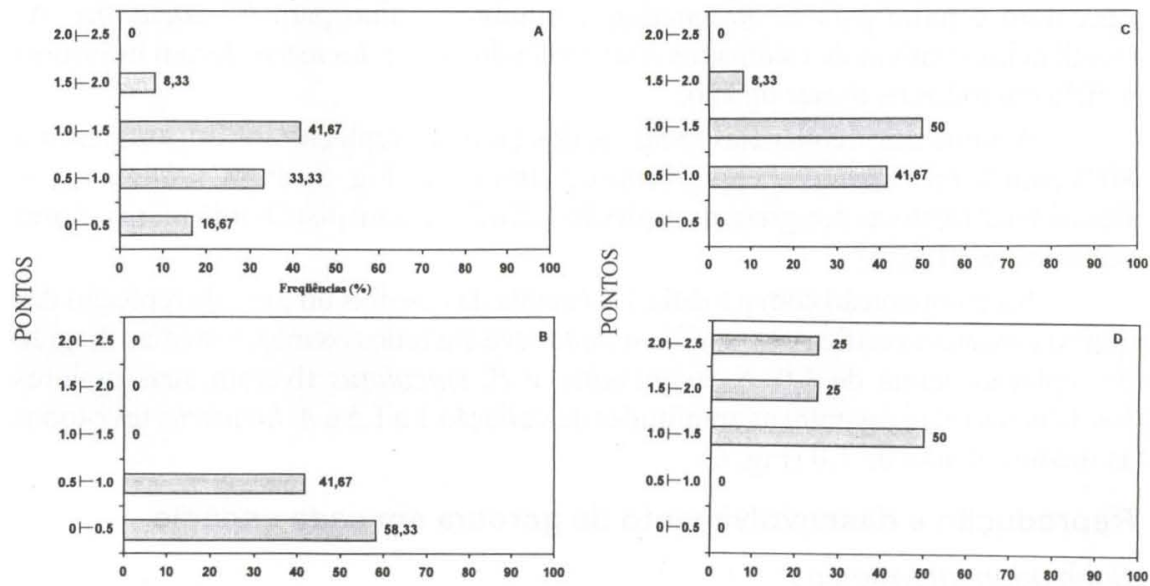

Fig. 6. Freqüências relativas das médias dos graus de repleção em cinco classes de variação em (A) Schizodon intermedius, (B) Acestrorhynchus lacustris, (C) Pimelodus maculatus e (D) Steindachnerina insculpta.

\section{Pimelodus maculatus}

Em nenhum mês foram encontrados espécimes nos estágios maduro e desova. Apenas um exemplar em estágio desovado foi registrado no mês de dezembro e dois exemplares em repouso em cada mês de dezembro e abril, 


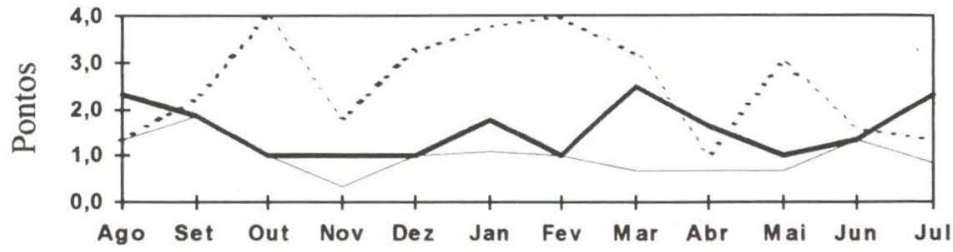

D

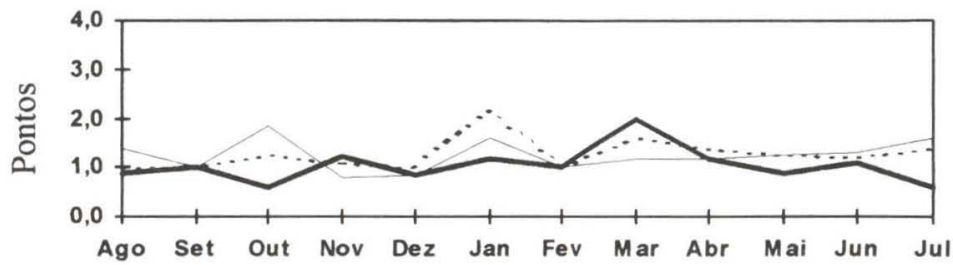

C

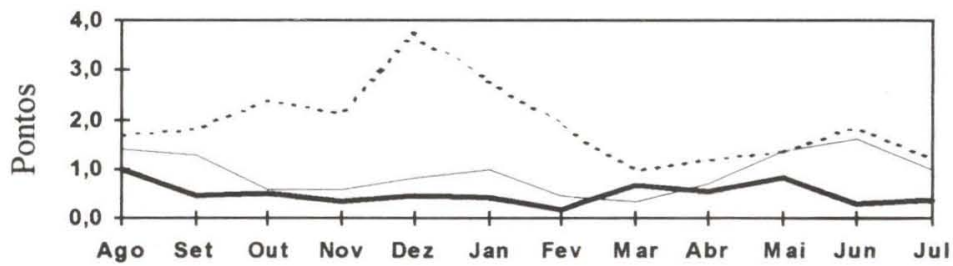

A

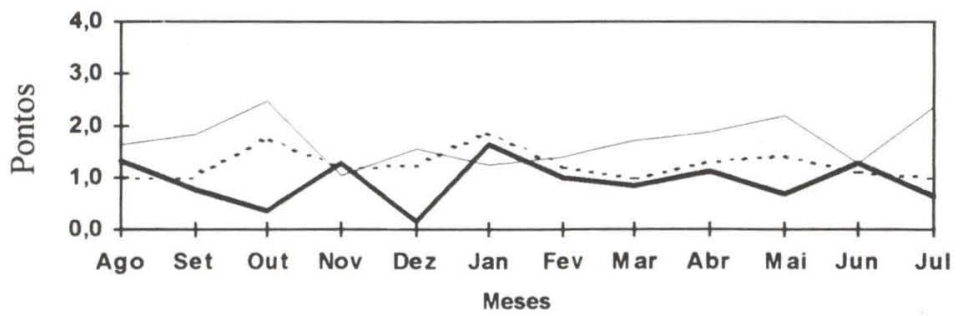

Fig. 7. Distribuição das médias dos graus de repleção (GR), de gordura (GG) e de maturação (GM) em (A) Schizodon intermedius, (B) Acestrorhynchus lacustris, (C) Pimelodus maculatus e (D) Steindachnerina insculpta. 
sugerindo que esta espécie provavelmente desove em locais próximos ao local amostrado. As médias foram diferentes de 3,0 somente nos meses acima referidos (Fig. 7C).

Os maiores valores das médias do grau de gordura foram em outubro e julho $(1,85$ e 1,62). Esses valores ocorreram durante os mesmos meses que ocorreram os menores valores das médias dos graus de repleção $(0,57$ e 0,61$)$, como é mostrado na figura $7 \mathrm{C}$.

\section{Acestrorhynchus lacustris}

Em dezembro foi verificado maior quantidade de indivíduos maduros (35), que coincide com a época de maior GM (Fig. 7B). Foram observados exemplares com atividade reprodutiva (estádios maduro, desova e desovado) desde outubro até fevereiro. Ainda, foram verificados nos meses de abril, com um exemplar e maio e julho, com dois exemplares, em estádio maduro.

As médias dos graus de gordura tiveram seus picos em agosto e junho $(1,42$ e 1,62 ). Durante o período de maior atividade reprodutiva os valores do GG mantiveram-se todos abaixo do valor 1,0 (Fig. 7B).

\section{Steindachnerina insculpta}

Esta espécie foi verificada em contínua atividade reprodutiva em vários meses. Em outubro e fevereiro todos os indivíduos estavam em estágio maduro. Esses dois meses, mais o mês de maio (com os exemplares em estágio maduro e desova) foram os meses de maior Gm (Fig. 7D).

Somente em cinco meses (agosto, setembro, novembro, junho e julho) não foram constatados espécimes em atividade reprodutiva. Nesses meses a média de GM permaneceu com valor 3,0 (Fig. 7D).

\section{DISCUSSÃO}

Foram verificadas variações quantitativas e/ou temporais distintas na atividade alimentar entre as quatro espécies estudadas. O trecho do rio Tibagi estudado não apresentou acentuada variação no regime hídrico e, além do que, é importante mencionar que estas espécies têm seu alimento principal de origem autóctone. As variações da atividade alimentar podem estar influenciadas pelo regime hídrico, mas não quanto a dependência ao acesso do alimento, como em outros rios neotropicais citados em GouLding (1980), JUNK (1985), Lowe-MCCONNELL (1987) e MACHADO-ALLISSON (1992).

Aventou-se então a hipótese do próprio alimento estar funcionando como fator limitante na atividade alimentar e reprodutiva das espécies. No entanto, $S$. intermedius caracterizada por YABE \& BENNEMANN (1994) como herbívora, não teve na vegetação aquática um fator limitante. As macrófitas Salvinia auriculata, Eichhornia crassipes, Pistia sp. e gramíneas, embora tivessem variação na quantidade disponível, sempre estiveram presentes no ambiente, durante o período estudado. Da mesma forma, a principal presa de A. lacustris foi Astyanax bimaculatus; insetos jovens e adultos e outros itens disponíveis foram os principais itens comidos por $P$. maculatus; o item "detrito" ingerido por $S$. insculpta, não sugere ser um fator limitante, pois sempre estiveram presentes no ambiente. 
As análises mostraram para as quatro espécies estudadas, médias semelhantes de graus de repleção para $S$. intermedius e $P$. maculatus. Essas duas espécies, embora sejam semelhantes no aspecto da variação da quantidade de alimento ingerido, relativamente baixo durante os doze meses do ano, tiveram épocas de menor e maior atividade alimentar em períodos diferentes. A distinção da época de menor e maior atividade alimentar destas duas espécies pode ser explicada pelos distintos regimes alimentares e outros fatores biológicos. Peixes de regime herbívoro não possuem estratégias específicas para a captura de alimento, suas adaptações são basicamente estruturais (GouLDING 1980). Schizodon intermedius, que se alimenta basicamente de macrófitas, pode comer durante todo o ano e as variações da atividade alimentar e reprodutiva neste estudo mostraram que, logo após o período de maior atividade alimentar, ocorre acúmulo de gordura.

$P$. maculatus, de regime onívoro, foi uma espécie com alta frequência relativa de estômagos com conteúdo alimentar, demonstrando possuir constância na sua alimentação. Os resultados de BASILE-MARTINS (1986a) com P. maculatus, concordam com os presentes, citando esta espécie como de dieta variada e de frequência alimentar constante. Da mesma forma, GoulDING (1980) verificou uma média baixa de conteúdo estomacal em Pimelodus sp., mencionando que é mais difícil para peixes onívoros encherem seus estômagos ao máximo.

Não foi possível caracterizar a atividade reprodutiva de $P$. maculatus, mas pode ser verificado que existe uma relação entre o desenvolvimento de gordura com a atividade alimentar. Felizmente, em estudos anteriores no rio Tibagi, foram observados exemplares maduros e em desova na localidade de Londrina (trecho do rio próximo a Sertanópolis), mas não em Sertanópolis, onde o rio tem características semi-lênticas. Essas observações concordam com as de BASILE-MARTINS et al. (1986b) que mostraram que os espécimes jovens desta espécie se deslocam rio acima, à área de reprodução, a medida que se desenvolvem.

Em relação aos demais regimes alimentares, a espécie carnívora-ictiófaga, A. lacustris, foi a que apresentou menores médias do grau de repleção durante quase todos os meses estudados. A baixa atividade alimentar de peixes piscívoros é esperada segundo NIKOLSKY (1963) e pode ser explicada pelo melhor aproveitamento e valor nutricional do alimento, o que torna a sua tomada menos frequente. Uma alta incidência de estômagos vazios de várias espécies carnívoras-ictiófagas foi também encontrada por GoULDING (1980) e CRUZ et al. (1990).

Segundo Goulding (1980), além de baixas médias, também não ocorreram grandes variações sazonais na repleção estomacal de peixes piscívoros. Verifica-se que A. lacustris teve as médias do grau de repleção baixas durante o período reprodutivo, outubro a fevereiro, com tendência levemente superior antes e após esse período. Dentre as quatro espécies estudadas, a menor média do grau de repleção foi em $A$. lacustris. Todavia, foram verificadas nesta espécie, as maiores frequências de estômagos quase cheios, com grau 3 de repleção. Isto demonstra bem o hábito piscívoro desta espécie, onde apenas uma presa pode encher o estômago.

Ao contrário dos peixes carnívoros-piscívoros, peixes detritívoros devem ingerir grandes quantias de alimento, pois uma grande proporção não é digerida Bond (1979). Grupos como os Curimatidae e Prochilodontidae possuem como 
adaptação comportamental a ingestão de detritos de maneira constante (BowEN 1983). WOOTTON (1990) ainda adiciona que o alimento dos detritívoros é de baixo conteúdo energético e devido a isso, precisam comer continuamente. Na espécie detritívora, $S$. insculpta, aqui estudada, os resultados refletiram um comportamento alimentar que os autores acima mencionam, pois todos os exemplares verificados continham alimento no estômago. Além disso, foi a espécie que teve a maior média do grau de repleção.

Os baixos graus de gordura verificados para $S$. insculpta podem, em parte, estar associados ao tipo de alimento ingerido. Ou ainda, ao fato de que espécies de menor porte acumulam menores quantidades de gordura, como observou GoULDING (1980). Realmente, S. insculpta, junto com A. lacustris, foram as duas espécies de menor porte e que tiveram as menores médias dos graus de gordura.

Por outro lado, no caso de $S$. insculpta, ficou evidente que a gordura foi gasta nas atividades reprodutivas. As médias do grau de gordura estavam baixas quando todos os exemplares estavam maduros, em outubro e fevereiro e também logo após os meses seguintes de intensa atividade reprodutiva, novembro e março. BOND (1979), cita que os peixes diminuem ou cessam a alimentação nos meses em que estão se reproduzindo. Nos meses de outubro e fevereiro, quando todos os exemplares de $S$. insculpta estavam maduros, ocorreram as menores médias do grau de repleção.

Considerando que o habitat no trecho do rio Tibagi (Sertanópolis), durante o período estudado, foi bastante uniforme, parece ter influenciado para a caracterização da relação das atividades alimentar/armazenamento de gordura/reprodução das quatro espécies quanto a sazonalidade não marcante dessas atividades, em função do habitat, parecendo o que SCHWASSMANN (1992) relata para espécies de pequeno porte e que vivem em riachos com florestas, sendo ambientes bastante uniformes, durante todo o ciclo anual.

Assim, as variações de épocas e intensidades dessas atividades e suas relações são atribuídas ao tipo de dieta, porte da espécie e padrão reprodutivo. Em duas das espécies (S. insculpta e A. lacustris) que tiveram bem evidenciadas atividades reprodutivas na área estudada, pode ser constatada claramente a sequência dos eventos: maior atividade alimentar, armazenamento de gordura e ocorrência da reprodução, conforme pode ser visualizado na tabela I.

AGRADECIMENTOS. Este estudo teve suporte financeiro pelo convênio UEL/COPATI/ KLABIN e auxílios suplementares do CNPq e da CAPES. Agradecemos ao Sr. Manoel Reis que gentilmente permitiu a utilização de sua propriedade rural próxima ao rio. $\dot{A}$ Ângela Teresa Silva-Souza e Lúcia Giuliano-Caetano, que coordenaram o grupo de estudos ictiológicos nesta fase de pesquisa. Agradecemos muito às pessoas que nos ajudaram nas coletas, particularmente Mauro Caetano Filho, Ricardo Siqueira, Edson Santana e Jacson Franco Bennemann, que trabalharam no barco independente da hora, frio, vento e sol. À Angela Maria Veregue, Alda Maria Borgui e Ana Karina Varoni pela coleta de dados das gônadas dos peixes estudados. À Claudia Bueno dos Reis Martinez pela ajuda e comentários deste manuscrito. Finalmente, à Priscila Lazoski pela confecção das figuras. 
Tabela I. Quadro comparativo entre as atividades alimentar/armazenamento de gordura e reprodutiva nas auatro espécies estudadas. no período Aaosto/1992 - Julho/1993.

\begin{tabular}{|c|c|c|c|c|c|c|c|c|c|c|c|c|}
\hline & AGO & SET & OUT & NOV & DEZ & JAN & FEV & MAR & ABR & MAI & JUN & JUL \\
\hline \multicolumn{13}{|l|}{$\begin{array}{l}\text { S. intermedius } \\
\text { Atividade alimentar }\end{array}$} \\
\hline \multicolumn{13}{|l|}{ Armazenamento de gordura } \\
\hline \multicolumn{13}{|l|}{ Atividade reprodutiva } \\
\hline \multicolumn{13}{|l|}{ P. maculatus } \\
\hline \\
\hline \multicolumn{13}{|l|}{$\begin{array}{l}\text { Atividade alimentar } \\
\text { Armazenamento de gordura }\end{array}$} \\
\hline Atividade reprodutiva & & & & & & & $?$ & & & & & \\
\hline \multicolumn{13}{|l|}{$\begin{array}{l}\text { A. lacustris } \\
\text { Atividade alimentar }\end{array}$} \\
\hline \multicolumn{13}{|l|}{ Atividade alimentar } \\
\hline \multicolumn{13}{|l|}{ Armazenamento de gordura } \\
\hline \multicolumn{13}{|l|}{ Atividade reprodutiva } \\
\hline \multicolumn{13}{|l|}{ S. insculpta } \\
\hline \multicolumn{13}{|l|}{ Atividade alimentar } \\
\hline Armazenamento de gordura & & & & & & & & & & & & \\
\hline Atividade reprodutiva & & & & & & & & & & & & \\
\hline
\end{tabular}

1. Picos de atividades (maiores GR e GG) e individuos em atividade reprodutiva (estádios maduro, desova e desovado).

? Possivel época de reprodução, segundo GodinHo et al. (1977).

\section{REFERÊNCIAS BIBLIOGRÁFICAS}

Basile-Martins, M.A.; M.N. Cipolli \& H.M. Godinho. 1986a. Alimentação do mandi, Pimelodus maculatus Lacépède, 1803 (Osteichthyes, Pimelodidae), de trechos dos rios Jaguari e Piracicaba, São Paulo - Brasil. Bol. Inst. Pesca 13 (1): 17-29.

Basile-Martins, M.A.; H.M Godinho; M.Y. Narahara; N. Fenerich-Verani \& M.N. CiPÓLLI. 1986b. Estrutura da população e distribuição espacial do mandi, Pimelodus maculatus Lacépède, 1803 (Osteichthyes, Pimelodidae) de trechos dos rios Jaguari e Piracicaba, São Paulo - Brasil. Bol. Inst. Pesca 13 (1): $1-16$.

Bond, C.E. 1979. Biology of fishes. Saunders College Publishing, Philadelphia, $514 \mathrm{p}$.

Bowen, S.H. 1983. Detritivory in neotropical fish communities. Env. Biol. Fish. 9 (2): 137-144.

Cruz, J.A.; J.A. Moreira; J.R. Verani; L. Girardi \& C.E.C. Torloni. 1990.

Levantamento da ictiofauna e aspectos da dinâmica de população de algumas espécies do reservatório de Promissão, SP (1 ${ }^{\text {a }}$ etapa). São Carlos, CESP/UFSCar, 78p.

Goulding, M. 1980. The fishes and forest: exploration in Amazonian Natural History. Berkeley, University of California Press, 280p.

GodINHO, H.M. 1994. Biologia reprodutiva da piaba-facão, Triportheus guentheri (Characiformes, Characidae) e o manejo hidrológico da represa de Três Marias. Rev. Brasil. Biol. 54 (3): 515-524.

JUNK, W.J. 1985. Temporary fat storage, an adaptation of some fish species to the water level fluctuations and related enviromental changes of the Amazon river. Amazoniana 9 (3): 315-351.

Lowe-MCCONNELL, R.H. 1987. Ecological studies in tropical fish communities. 
Cambridge, University press, 382p.

MACHADO-ALLISSON, A. 1992. Larval ecology of fish of Orinoco Basin, p.45-59. In: W.C. HAMLETT (Ed.). Reproductive biology of South American vertebrates. New York, Springer, 328p.

NiKolsky, G.V. 1963. The ecology of fishes. London, Academic Press, 352p.

SANTOS, G.M. 1982. Caracterização, hábitos alimentares e reprodutivos de quatro espécies de Aracus e considerações ecológicas sobre o grupo no lago Janauacá - AM (Osteichthyes, Characoidei, Anostomidae). Acta Amazônica 12 (4): 713-739.

SchwasmanN, H.O. 1992. Seasonality of reproduction in Amazonian fishes, p.71-81. In: W.C. HAMLETT (Ed.). Reproductive biology of South American vertebrates. New York, Springer, 328p.

WootTON, R.J. 1990. Ecology of teleost fishes. London, Chapman and Hall, 404p. YABE, R.S \& S.T. BENNEMANN. 1994. Regime alimentar de Schizodon intermedius Garavello \& Britski do rio Tibagi, Paraná, e sua relação com algumas características morfológicas do trato digestivo (Osteichthyes, Anostomidae). Revta bras. Zool. 11 (4): 777-788.

Recebido em 30.XI.1995; aceito em 17.X.1996. 